\title{
THE ANALYSIS OF THE CORRELATIONS AND REGRESSIONS BETWEEN SOME CHARACTERS ON A WHEAT ISOGENIC VARITIES ASSORTMENT
}

\author{
PÄNITĂ Ovidiu \\ University of Craiova, Faculty of Agriculture and Horticulture, ovixfp@yahooo.com
}

\begin{abstract}
In the years 2012-2014 on Banu-Maracine DRS there were tested an assortment of 25 isogenic lines of wheat (Triticum aestivum ssp.vulgare), the analyzed characters being the number of seeds/spike, seeds weight/spike ( $g$ ), no. of spikes $/ \mathrm{m}^{2}$, weight of a thousand seeds (WTS) $(\mathrm{g})$ and no. of emerged plants $/ \mathrm{m}^{2}$. Based on recorded data and statistical processing of those, they were identified a numbers of links between these characters. Also available regression models were identified between some of the studied characters. Based on component analysis, no. of seeds/spike and seeds weight/spike are components that influence in excess of $88 \%$ variance analysis, a total of seven genotypes with positive scores for both factors.
\end{abstract}

Key words: Yield elements, forecasting regression model, principal component analysis

\section{Introduction}

The spikeliest cultivated forms of wheat were essentially landraces selected by farmers from wild populations, presumably because of their superior yield and other characteristics, an spikely and clearly non-scientific form of plant breeding! However, domestication was also associated with the selection of genetic traits that separated them from their wild relatives [4].

The spread of wheat from its site of origin across the world has been elegantly described by Feldman [3]. The achievement of a genetic diversity by cultivating more genotypes with different reactions at the conditions of environment, with different precocity, constitutes the simplest way of reduction the fluctuation of the yield to plant crop [2].

Generally, the seeds are a good start for the future culture, if they have a high biological value, coming from improved genotypes with the genetic, physiological and morphological index of quality. From this point of view, a high mitotic activity is directly proportional to the genetic viability of the seed. Analysis of the mitotic activity and the mitotic division indexes can reveal the genotypic specificity and genetic diversity [1].

Regarding the phenomenon of dwarfing on wheat, genetic bases are determined by $R h t$ genes type that is known to breeders for over 40 spikes and although it has been extensively used in wheat, this gene cannot be transferred on other cereals [6]. Worldwide, there are not yet fully known $R h t$ genes effects that they have on the plant, but it seems that their actions are multiple, affecting more than plant height [7]. Varieties with high straw secure better sunlight, butt end to break under its own weight because of the fragility stem. Fertilization with nitrogen, vital in crop conditions on soils with low and very low fertility, cannot be applied in this situation, since the plants are breaking or semi-dwarf varieties have no longer problems regarding fertilization [5].

\section{Material and method}

In the years 2012-2014 on Banu-Maracine DRS were tested an assortment consists of 25 isogenic lines of common wheat (Triticum aestivum ssp. vulgare), with the combination of rht $\&$ Rht8 genes, the analyzed characters being the number of seeds/spike, the seeds weight/spike ( $\mathrm{g}$ ), the no. of spikes $/ \mathrm{m}^{2}$, the weight of a thousand seeds (WTS) (g) and the no. of emerged plants $/ \mathrm{m}^{2}$. The links between characters were analyzed be using the correlations and the regressions.

The evolution of the studied characters was monitored using forecasting regression models based on linear or nonlinear regression using polynomial equations. Validity forecasting regression models was determined by using the coefficient of determination $\left(\mathrm{R}^{2}\right)$, the available models having a coefficient of determination greater than 0.7 . Regarding the interpretation of the correlation coefficient value, it was considered that when this is positive, the relationship between variables $\mathrm{X}$ and $\mathrm{Y}$ is "positive", namely an increase of $\mathrm{X}$ value character determines the overall growth of character $\mathrm{Y}$. 
When correlation coefficient value relationship between the two variables is "negative", an increase of $\mathrm{X}$ character generally has as a consequence a decrease of $\mathrm{Y}$ character. The interpretation of the correlation coefficient was applied according Colton (1974.). In our experiment there were consider that correlation which have a correlation coefficient value higher than \pm 0.7 . The regression forecasting models were calculated using polynomial equations. The regression model is considered valid when was calculated a coefficient of determination greater than 0.7 . The coefficient of determination was based on the correlation coefficient, which is equal to the square of the correlation coefficient.

\section{Results and discussions}

Regarding the analyzed yield elements in Table 1 there is presented the variation of main parameters calculated. Thus, regarding the average no. of seeds/spike, it had a value of 20.37 seeds/spike with a standard deviation of 2.94 seeds/spike, limits of variation between 14.55 and 25.25 seeds/spike and an amplitude variation of 10.7 seeds/spike (Table 1). Regarding the seeds weight/spike, the average was $0.876 \mathrm{~g}$ seeds/spike, with a standard deviation of $0.16 \mathrm{~g}$ seeds/spike, limits of variation between 0.61 and 1.28 seeds/spike and an amplitude variation of $0.67 \mathrm{~g}$ seeds/spike.

Table 1: The variation of calculated parameters for the studied character

\begin{tabular}{|l|c|c|c|c|c|}
\hline Parameter & $\begin{array}{c}\text { No of } \\
\text { seeds/spike }\end{array}$ & $\begin{array}{c}\text { Seeds } \\
\text { weight/spike } \\
(\mathrm{g})\end{array}$ & $\begin{array}{c}\text { No. of } \\
\text { spike/m² }\end{array}$ & $\begin{array}{c}\text { WTS } \\
(\mathrm{g})\end{array}$ & $\begin{array}{c}\text { No. of } \\
\text { emerged } \\
\text { plants/m }\end{array}$ \\
\hline Average & 20.37 & 0.876 & 565.12 & 44.63 & 335.36 \\
\hline Range & $14.55-25.25$ & $0.61-1.28$ & $387-664$ & $40-49.2$ & $229-410$ \\
\hline Variation amplitude & 10.7 & 0.67 & 277 & 9.2 & 181 \\
\hline Standard deviation & 2.94 & 0.16 & 77.64 & 2.71 & 48.47 \\
\hline $\begin{array}{l}\text { Variability } \\
\text { coefficient }\end{array}$ & 14.43 & 18.26 & 13.74 & 6.07 & 14.45 \\
\hline
\end{tabular}

Regarding the no. of spikes $/ \mathrm{m}^{2}$, the average was $565.12 \mathrm{spikes} / \mathrm{m}^{2}$, with a standard deviation of 77.64 spikes $/ \mathrm{m}^{2}$, limits of variation between 387 and 664 spikes $/ \mathrm{m}^{2}$ and an amplitude of variation of 277 spikes $/ \mathrm{m}^{2}$. Regarding the WTS, the average was $44.63 \mathrm{~g}$, with a standard deviation of $2.71 \mathrm{~g}$, limits of variation between 40 and $49.2 \mathrm{~g}$ and $9.2 \mathrm{~g}$ amplitude variation. In the case of no. of emerged plants $/ \mathrm{m}^{2}$, the average was 335.36 emerged $\mathrm{pl} . / \mathrm{m}^{2}$, with a standard deviation of $48.47 \mathrm{emerged} \mathrm{pl} . / \mathrm{m}^{2}$, the variation range between 229 and 410 emerged $\mathrm{pl} . / \mathrm{m}^{2}$ and a variation amplitude of 181 emerged $\mathrm{pl} . / \mathrm{m}^{2}$.

In the present study, regarding the study on correlations between the studied characters, these are shown in Table 2. Thus, we identified strong links between:

- The no. of seeds/spike and seeds weight/spike, the correlation coefficient being of 0.824 .

- The no. of seeds/spike and WTS, the correlation coefficient being equal with-0.822.

- The seeds weight/spike and WTS, the correlation coefficient being of -0.745 .

- The emerged plants $/ \mathrm{m}^{2}$ and no. of spikes $/ \mathrm{m}^{2}$, the correlation coefficient being of 0.841 .

Table 2: The analysis of the correlation coefficients between the studied characters

\begin{tabular}{|c|c|c|c|c|}
\hline Character & $\begin{array}{c}\text { No. of } \\
\text { seeds/spike }\end{array}$ & $\begin{array}{c}\text { Seeds } \\
\text { weight/spike }\end{array}$ & $\begin{array}{c}\text { No. of } \\
\text { spike } / \mathrm{m}^{2}\end{array}$ & WTS \\
\hline Seeds weight/spike & 0.824 & - & - & - \\
\hline No. of spike $/ \mathrm{m}^{2}$ & 0.037 & 0.057 & - & - \\
\hline WTS & -0.822 & -0.745 & -0.075 & - \\
\hline $\begin{array}{l}\text { No. of emerged } \\
\text { plants } / \mathrm{m}^{2}\end{array}$ & 0.122 & 0.145 & 0.841 & -0.096 \\
\hline
\end{tabular}

From the analysis of the calculated correlation coefficients, the following predictions can be made regarding the biological mechanisms, as follows:

-Large negative value of the correlation coefficient between WTS and no. of seeds/spike, suggests that with increasing no. of seeds in the spike, their size of those decreases.

-The high value of the correlation coefficient between no. of seeds/spike and seeds weight/spike, naturally suggests that once the increase the no. of seeds in the spike, clearly and seeds weight increases too. In conclusion, when it grows no. of seeds/spike, decreasing their size of the seeds, but also increases the average weight of seeds produced by a spike, despite the decrease in seeds size. Concerning the regression analysis models available depending on the value of the correlation coefficient, in the case of regression model between the no. of seeds/spike and seeds 
weight/spike, it was calculated a regression equation of degree 4 polynomial type, the coefficient of determination equal to 0.711 (Chart 1).

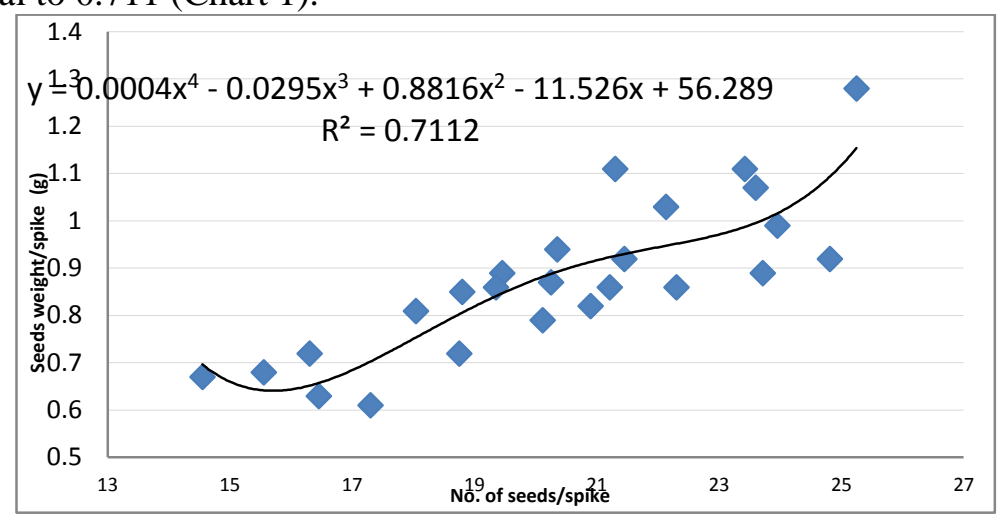

Chart 1-The regression model analysis between no. of seeds/spike wand seeds eight/spike

Regarding the regression model analysis of emerged plants $/ \mathrm{m}^{2}$ and no. of spikes $/ \mathrm{m}^{2}$ it was calculated the linear regression equation, the coefficients of determination being equal with 0.7079 , while the value of the regression coefficient was 1.347, which means that, when the no. of emerged plants $/ \mathrm{m}^{2}$ increases with one unit, no. of spikes $/ \mathrm{m}^{2}$ increases with 1.347 (Chart 2).

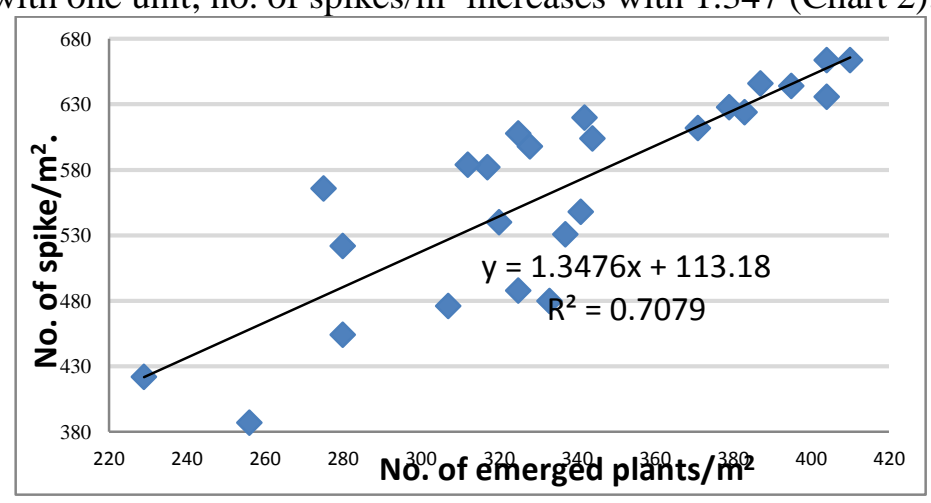

Chart 2 - The regression model analysis between no. of emerged plants $/ \mathrm{m}^{2}$ and no. of spikes $/ \mathrm{m}^{2}$

Concerning the regression analysis models available depending on the value of the correlation coefficient, in the case of regression model between the no. of seeds/spike and WTS, it was calculated a regression equation of degree 4 polynomial type, the coefficient of determination was equal with 0.744 (Chart 3).

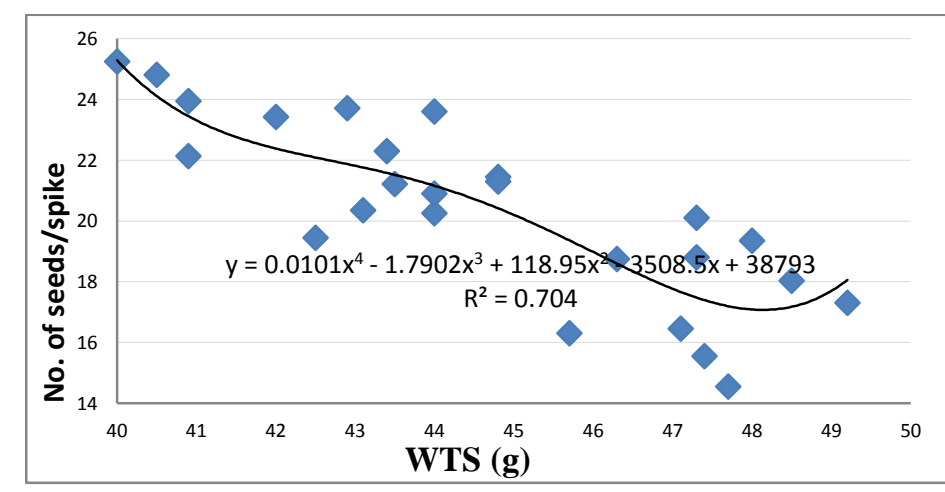

Chart 3 - The regression model analysis between no. of seeds/spike and WTS

In the present study it was carried out and principal components analysis (PCA). Thus the first two factors, namely no. of seeds/spike and seeds weight/spike influenced the variance to an extent of $88.78 \%$ (Table 3 ).

In this analysis, based on two components that scored the highest, there were identified the following groups (Chart 4): group I with seven genotypes, in which both components have positive scores; group II with eight genotypes, the first component has positive values and the second component is negative; group III genotypes having 5, where in both components have negative scores; group IV genotypes having 5, where the first component is negative and the second component is positive. 
Table 3: Eigenvalues and component score coefficients

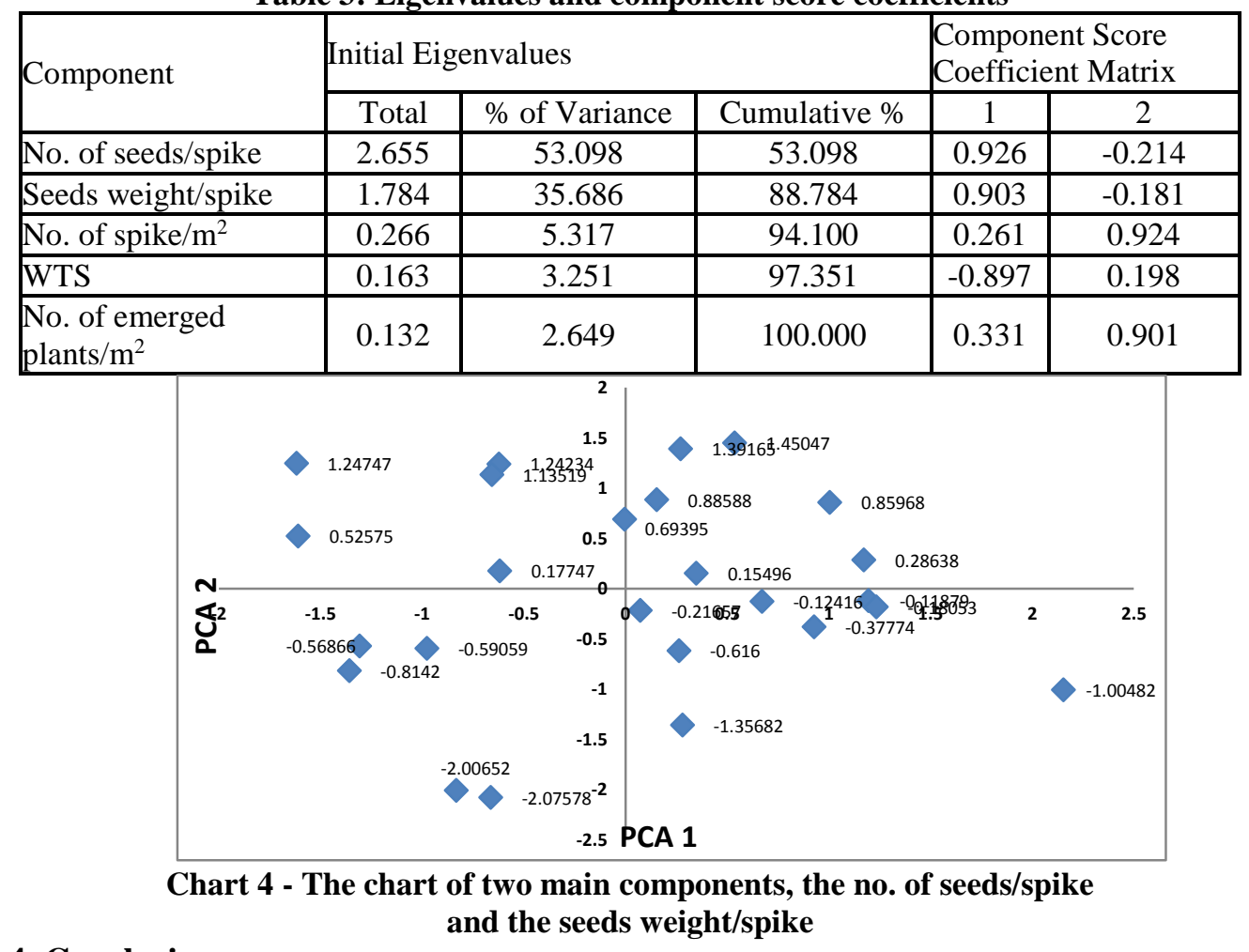

\section{Conclusions}

Based on recorded data and statistical processing of it, it can draw the following conclusions: 1. Strong links were found between the no. of seeds/spike and seeds weight/spike, the no. of seeds/spike and WTS, the seeds weight/spike and WTS, the no. of emerged plants $/ \mathrm{m}^{2}$ and the no. of spikes $/ \mathrm{m}^{2}$.

2. Based on the calculation of the coefficient of determination, the regression models were identified between the no. of seeds/spike and the seeds weight $/ \mathrm{spike}$, the no. of emerged plants $/ \mathrm{m}^{2}$ and the no. of spikes $/ \mathrm{m}^{2}$ and between the no. of emerged plants $/ \mathrm{m}^{2}$ and the no. of spikes $/ \mathrm{m}^{2}$.

3. On the basis of the correlation coefficients values, we can deduce that when it increase the no. of seeds/spike, it decreases their size, but also increase the average weight of seeds produced by a spike, despite the decrease in seeds size.

4. Based on the analysis of components, no. of seeds/spike and seeds weight/spike are components that influence in excess of $88 \%$ variance analysis, a total of seven genotypes having positive scores for both factors.

\section{Acknowledgments}

This work was supported by the strategic grant POSDRU/159/1.5/S/133255, Project ID 133255 (2014), coffinanced by the European Social Fund within the Sectorial Operational Program Human Resources Development 2007-2013

\section{References}

1. Bonciu, E., Variability of the mitotic activity to some foreign sunflower genotypes. Journal of Horticulture, Forestry and Biotechnology, Volume 17(3), p. 126-129. Editura Agroprint, Timişoara, (2013).

2. Bonciu, E., Iancu, P., Soare, M., Researches concerning some foreign sunflower genotypes behavior under the condition of red preluvosoil from the central area of Oltenia. Scientific Conference with international participation "Durable Agriculturte-Agriculture of future" the sixth edition and "The National Mycology Symposium", the XXII ${ }^{\text {nd }}$ Edition. Vol. XL/2 2010. p. 39-43, ISSN 1841-8317. Editura Universitaria, Craiova, (2010).

3. Feldman M. Origin of cultivated wheat. In: Bonjean AP, Angus WJ, editors. The world wheat book: a history of wheat breeding. Paris, France: Lavoisier Publishing;. p. 3-56. (2001)

4. Nalam V.J., \& co., Map-based analysis of genes affecting the brittle rachis character in tetraploid wheat (Triticum turgidum L.). Theoretical and Applied Genetics;112:373-381. (2006)

5. Păunescu, G. Codul decimal pentru stadiile de vegetație la grâu. Ed. Sitech, Craiova (2007).

6. Soare, M. Ameliorarea plantelor agricole. Partea specială. Editura Universitaria. Craiova, (2004).

7. Voica, N., Soare, M., Soare, P., Genetica vegetală. Editura Universitaria, Craiova (2004) 